\title{
Analysis on the production situation of new wall materials in each region of Hebei Province
}

\author{
Dezhi Meng ${ }^{1}$, Minghui Cui ${ }^{1 *}$, Xiaoyong Liang ${ }^{1}$ \\ 1 School of civil engineering, Hebei University of Science and Technology, Shijiazhuang, \\ 050018, P.C.China \\ 452507563@qq.com
}

Keywords: clay, new wall materials, market analysis, Regional analysis

Abstract. Based on practice data, this paper focused on the market supply and demand relation and used the systematic method to analyze the brick type, block type, heat preserved new wall materials in Hebei province. according to the amount of chimney and the number of new wall materials and production, this paper analyzed the circumstance each region will encounter after the full implementation of "Ban limit real sticky" post in 2016, and tried to find solutions. And provide practical reference for the future production and innovation of Chinese wall materials in other provinces.

\section{Introduction}

Under the condition that PM2. 5 in Hebei province remains, In this paper, in the Hebei Province People's Government Office on the went to the province of new wall materials screening and promotion application of subject group municipalities investigation notice and Hebei provincial wall materials innovation and building energy management office of carry out the province's new wall materials investigation notice Hebei Province, energy-saving office 2015 No, 5 file requirement under On May 5, 2015, "new wall materials census and application research" was held in Shijiazhuang in Hebei province, and on May 20, the research group set out to conduct various research activities on the new wall materials. And the research results are used to support the topic and paper research.

\section{The Rise and Fall of clay brick}

\section{The Development history of clay brick}

Ever since thousands of years ago, Chinese people have produced sintered clay brick. early in the Western Zhou Dynasty, clay has been used in the buildings, due to their simple and easily available raw materials, simple production process, high thermal stability high strength, and cheap price. clay bricks are widely used in our buildings, especially in the rural housing. But with China's economic development, environmental issues followed, sandstorms, haze, and other bad weather problems are becoming increasingly serious and sintered clay brick is one of the important factors. Sintered clay brick not only destroyed the land, but also generated a lot of serious pollution sulfide, carbon dioxide, and atmospheric dust and other products. , since 1992 a series of policies has been developed to ban clay and promote a new green energy-saving alternative to clay brick wall products and clay products in Hebei Province. By the end of 2015, it plans to shut down all the solid brick kiln. 


\section{Present situation of each region's dismantling of brick kilns}

Each city or provincial tube county (city) 's process in banning solid brick kiln is provided in the following table.

\begin{tabular}{cccccc}
\hline Name & $\begin{array}{c}\text { Full-year } \\
\text { target }\end{array}$ & $\begin{array}{c}\text { The } \\
\text { completed } \\
\text { task before } \\
\text { June 26 }\end{array}$ & $\begin{array}{c}\text { June 28 } \\
\text { focused } \\
\text { action }\end{array}$ & $\begin{array}{c}\text { Completio } \\
\text { n } \\
\text { percentage }\end{array}$ & $\begin{array}{c}\text { The remaining } \\
\text { tasks }\end{array}$ \\
\hline Hebei Province & 2780 & 440 & 230 & $24 \%$ & 2110 \\
Shijiazhuang & 394 & 28 & 18 & $12 \%$ & 348 \\
Chengde & 186 & 186 & 0 & $100 \%$ & 0 \\
Zhangjiakou & 140 & 6 & 13 & $14 \%$ & 121 \\
Qinhuangdao & 60 & 5 & 26 & $52 \%$ & 29 \\
Tangshan & 52 & 6 & 15 & $40 \%$ & 31 \\
Langfang & 126 & 11 & 22 & $26 \%$ & 93 \\
Baoding & 390 & 82 & 18 & $26 \%$ & 290 \\
Cangzhou & 357 & 9 & 18 & $8 \%$ & 330 \\
Hengshui & 223 & 64 & 28 & $41 \%$ & 131 \\
Xingtai & 366 & 26 & 45 & $19 \%$ & 295 \\
Handan & 486 & 17 & 27 & $9 \%$ & 442 \\
\hline
\end{tabular}

Number of chimney brick indirectly reflects the number of enterprises. The more number of chimney indicates greater overshoot the "no real limit stick" policy brings to the local construction market, And when local production of new wall materials is insufficient, there will be increasing risks in the market.

\section{Development of new wall materials}

\section{Types and advantages of new wall materials}

The various new wall materials can be divided into four categories, including brick type, block type, insulation type and plate type. Such as the well-known green bricks (also known as garbage transfer). using construction waste which exceeds the national standard for nearly 20 percent as original material, the recorded factories' production abandons the sintering process, reduces air pollution, and consumes the waste, meeting the meet Market demand to some extent.

\section{The production of new wall materials}

According to research data, , the province's total new wall materials and thermal insulation materials Enterprise have reached 1085 by the end of 2014, forming three categories including non-clay brick, brick, wall insulation materials and over 30 varieties. Wherein the enterprises which produce non-clay class have reached 494, their annual production capacity is about 18.32 billion standard bricks; the 279 block class production enterprises have an annual production scale of about 37,896,000 m3; There are also 312 wall insulation materials production enterprises with annual production capacity of about $415,328,000$ square meters. By the general survey and focused research method, this paper explored 804 new wall materials enterprises, involving eleven cities 
and ten provinces pipe county. According to survey data we divide new wall materials enterprises into the non-clay brick, production the brick, production and wall insulation materials production, separately analyzing the number of enterprises, the production scale, the actual annual production and annual production scale ratio, etc.

\section{Production of brick materials}

The production of new type brick in Zhangjiakou, Tangshan, Cangzhou, Qinhuangdao, Xingtai Chengde is large, that in Handan, and Hengshui is less, and the rest regions' is small. In each region Except Shijiazhuang, the ratio of actual annual brick production and annual production scale ranges from 0.4 to 0.7 , indicating that the province's new brick market is differently affected by the red brick market. Once the "no stick to the real"policy is fully implemented, each region would rely on full load production to meet the demand of brick Market.

\section{Production situation of block material}

The production of block material in Zhangjiakou, Tangshan, Cangzhou, Qinhuangdao, Xingtai Chengde is large, that in Handan, and Hengshui is less, and the rest regions' is small. In most regions, the ratio of actual annual block material production and annual production scale ranges from 0.4 to 0.6. the ratio of actual annual output and annual production scale in Qian'an, Langfang, Shijiazhuang is larger, indicating that application of new block type there is good, and the "no stick to the real"policy is well applied. But on the whole the block market of the whole province is differently affected by the red brick market. Once the "no stick to the real"policy is fully implemented, each region would rely on full load production to meet the demand of block material Market

\section{Production of heat preservation material}

The production of heat preservation material in Tangshan, Zhangjiakou, Qian'an, Baoding, Xinji, Hengshui is large, that of the rest regions' is small. In most regions, the ratio of actual annual heat preservation material production and annual production scale ranges from 0.4 to 0.6 . the ratio of actual annual output and annual production scale in Qian'an, Langfang, Shijiazhuang is larger, indicating that application of heat preservation material there is good, and the "no stick to the real"policy is well applied. The ratio in dingzhou and huailai is less. But on the whole the heat preservation material market of the whole province is differently affected by the red brick market. Once the "no stick to the real"policy is fully implemented, each region would rely on full load production to meet the demand of heat preservation material Market 
The ratio of the number of enterprises in province to the total number of enterprises in Hebei Province

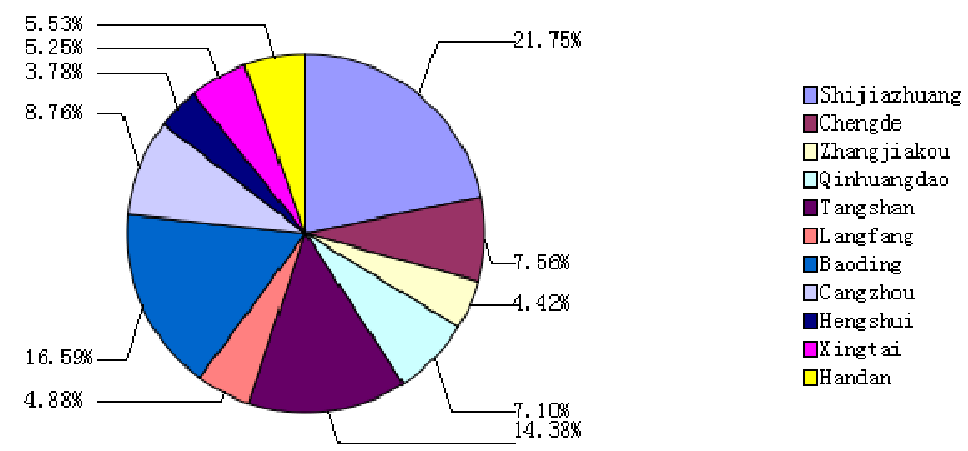

Figure 1 the new wall materials enterprises of the province's total area ratio

As is shown in Figure 1, enterprises in Shijiazhuang, Baoding, and Tangshan are more than $50 \%$ of the province's output. in other regions, the enterprise segment is not more but uniform. when the "no sticky limit" policy is fully implemented by 2016, Shijiazhuang, Baoding, Tangshan, will be the center to Deliver new wall materials to other cities.

\section{Production of new type brick in each region}
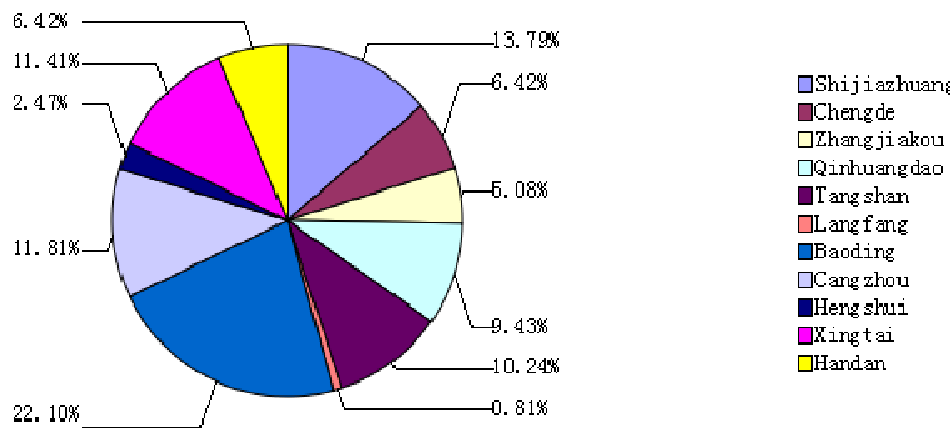

Figure 2 The ratio of the total output of the new type of brick to the total output of Hebei province.

As is shown Figure 2, brick production of Baoding, Shijiazhuang, Cangzhou, Xingtai, Tangshan, and Qinhuangdao will account for nearly $80 \%$ of the province's output. In central and southern Hebei province the production of new type of brick is larger. 


\section{Production of new type block in each region}

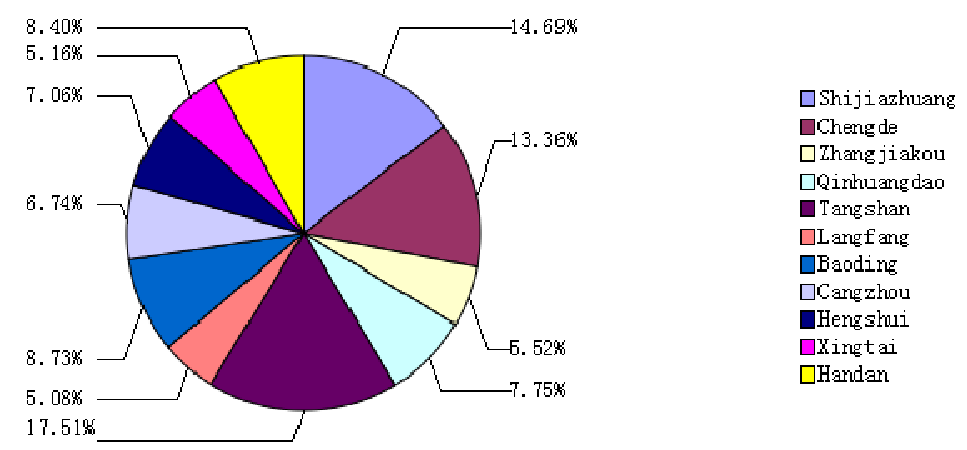

Figure 3 the ratio of new block output in each region and the total output of Hebei Province

As is shown in Figure 3, the output of Tangshan, Shijiazhuang, Chengde will account for $45.2 \%$ of the province's output, and the rest region's production is about flat.

\section{Production of new type heat preservation in each region}

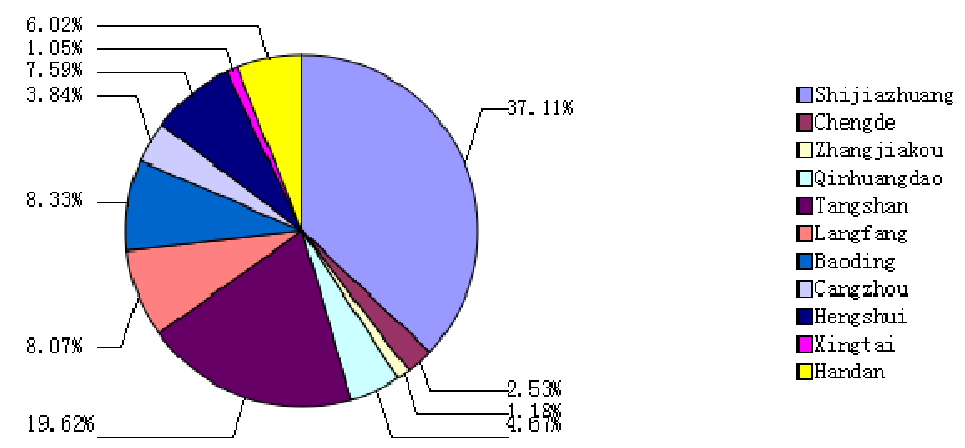

Figure 4 the ratio of new type heat preservation materials output in each region and the total output of Hebei Province

As is shown in Figure 4, the output of Shijiazhuang and Tangshan will account for $50 \%$ of the province, and production of the rest is not large. Once the "no sticky limit" policy is fully implemented, the insulation material Hebei Xingtai Zhangjiakou area may need to be imported from abroad.

\section{Conclusions}

(1) the eastern part and the western edge part of Hebei province can fully meet the market demand. after the implementation of "no sticky limit" policy in 2016. Most of the central region can basically meet the needs of the market.

(2) in central and Southern Hebei Province and most cities in Northern Hebei province, , new wall materials can meet the requirements of the market after the implementation of "no sticky limit" policy

(3)in the northern part of Zhangjiakou, northern Baoding, Eastern Shijiazhuang, Eastern Handan, and eastern Cangzhou, the new material production can not meet the needs of the market. there is a need for import.

(4) as to areas that cannot meet the requirements of the market, the government should carry on the macroeconomic regulation and control, subsidy for new wall materials enterprises and users, 
and develop green building materials star rating system to make people have a comprehensive understanding of new wall materials.

\section{Reference}

[1] Yihong LUO, Yunfei SHAO,Ting CHEN. Study of New Wall Materials Design Based on TRIZ Integrated Innovation Method[J]. Management Science and Engineering,2012,64

[2] R.C.M. Yam,D.M.T. Mak. A cleaner production of rice husk-blended polypropylene eco-composite by gas-assisted injection moulding[J]. Journal of Cleaner Production,2013

[3] Yoshiteru HORIKAWA. Special Reviews: Present Status and Future Issues of Interior Decorative Printing[J]. Journal of Printing Science and Technology,2001,381 